\title{
Removal of electrocardiogram distortion in portable high-power medical device
}

\author{
Hyung-Sik Kim ${ }^{1}$, Sung-Jun Park ${ }^{1}$, Tae Kyung $\mathrm{Ha}^{2}$, Jeong-Han $\mathrm{Yi}^{1}$ \\ ${ }^{1}$ Department of Biomedical Engineering, BK21+ Research Institute of Biomedical Engineering, College of Biomedical \& Health Science, \\ Konkuk University, Chungju, Chungbuk 380-701, South Korea
}

${ }^{2}$ Department of Surgery, College of Medicine, Hanyang University, Seoul, 133-791, South Korea

\begin{abstract}
In this study, we propose a method to remove bio-signal distortions generated when the power is at transient condition in a high-powered portable medical device. To verify the method, three units were designed that consists of a main control unit, bio-signal measurement unit, and power unit. Also, each units were separated with galvanic isolation. For stable operation at the surge condition, the power unit was composed using push-pull converter topology. The design has been examined in both transient and steady state of the operating conditions. The experiment result shows that galvanic isolation between each units was efficient in high-powered potable medical device.
\end{abstract}

\section{INTRODUCTION}

Recently, as medical emergency situations gain interest, the existing electronic medical devices used by connecting power-lines are gradually becoming portable $[1,2]$. Especially, as the criteria on ambulance become strict, developments on first-aid medical devices that are powered by compact batteries and stored in vehicles are in progress [3]. In addition, due to the improvement in standard of living, interest in health is increasing, the demand on compact portable medical device constantly raising with easy storage and convenient use to utilize even in a home [4].

Among these medical devices, automated external defibrillator (AED) has become an essential medical device with the tendency of increase in cardiovascular diseases, and each country advises to necessarily provide AEDs within public places, trains, cinemas, planes, and etc., $[5,6]$. To allow even the ordinary people to use AEDs at cardiac arrest, they are designed in simple and intuitive interfaces for automatic diagnosis of heart conditions, charging and delivery energies for defibrillations. Also, AEDs can be used in various environments because they are powered by batteries. However, since around 150 360 Joule of energy is needed for heart resuscitation, AED converts the low voltage of its inner battery to a high voltage up to about $1,500 \sim 2,000$ volts for capacitor. At this point, to increase the success rate of defibrillation, the voltage of the capacitor has to reach its target voltage in a short time. Therefore it needs a sophisticated power converter design that the size and the efficiency of the overall circuit is considered. Thus, for voltage conversion and fast charging, most of the AEDs are made consuming a lot of current for initial stage of charge. At this time, because of a lot of current from the battery is instantly delivered to the main circuit, bio-signal distortion occurs due to the noise generated from the operation of power converter and drop of battery voltage in a moment. For this reason, the bio-signal diagnostic software generates a wrong signal leading to malfunctioning of an AED. To prevent this condition, various methods are carried out to ensure stable operations such as in aspects of circuits (analogue circuit, power factor correction, and firmware) $[7,8]$ and software (electrocardiogram detection algorithm) [9, 10], however, the underlying is not being solved.

In this study, each of circuit units such as the main control, power, and bio-signal measurement unit was designed and separated by galvanic isolation to eliminate distortion of bio-signal at the transient condition of power source.

\section{Methods}

The configuration of the proposed system is presented in Figure 1. The overall system is controlled by ARM family microcontroller, STM32F103D (ST Microsystems, USA), positioned at the main control unit. This microcontroller is composed of a 32-bit CortexTM-M3 CPU, 112 GPIOs (general purpose input output), 21 channels of 12-bit ADC (analog-to-digital converter), 12 channels of DMA (direct memory access) with a maximum operating frequency of $72 \mathrm{MHz}$, and etc.,

To prevent mutual interference between each circuit units, galvanic isolation which is the electrical separation, 
is done by having different ground points of over two circuits. In this study, all 3 units are designed in the primary and secondary side. The units are all composed of active circuits, each side needs a power source independently. For the isolation barrier, the clearance is set to $3.5 \mathrm{~mm}$ according to the 'Means of Patient Protection (MOPP)' in the IEC60601-3rd edition presented by the international medical device standards [11].

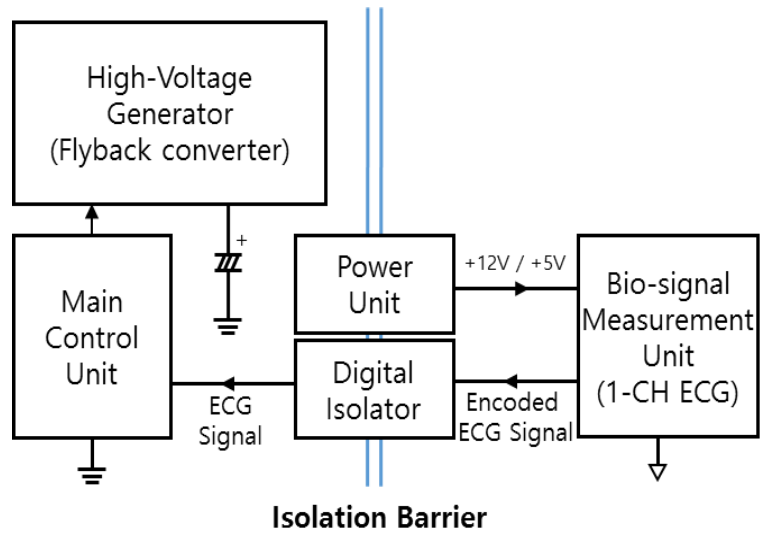

Figure 1. Overall configuration of proposed design.

\subsection{Main control unit}

The main control unit controls overall system operation, controls status, processing an external input, storage data and monitoring a system, etc. Also, it produces high voltage for heart defibrillation. The high voltage of 1,500 $\sim 2,000$ volts is generated from a battery voltage of 10.8 volts using fly-back power converter topology (Figure 2).

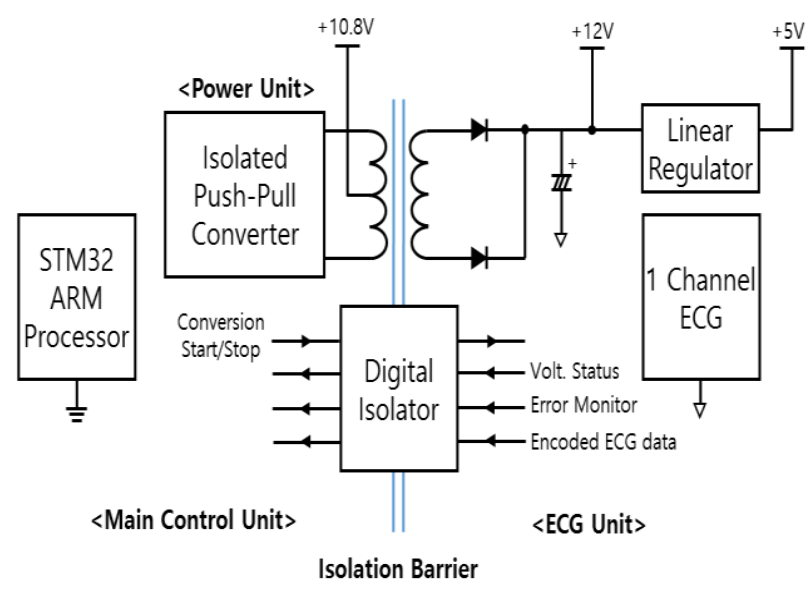

Figure 2. Implementation of main control, power, and biosignal measurement unit.

\subsection{Power unit}

The isolated push-pull converter topology is used for the power unit. Since this topology can be simply composed using two transistors and a small size transformer for isolation, it is widely used for compact systems. Considering the degree of voltage drop of the battery voltage, 10.8 volts, at high-voltage charge, the voltage at full charge of the battery, and the voltage drop by a longterm use, the unit is configured to reliably generate a power source of +12 Volts / 0.5 Amperes to the secondary side which is isolated in the range of $9.5 \sim 12$ volts. UC3845 current mode PWM converter (Texas Instruments, USA) and PMIC (power management integrated circuit) are used for the configuration. For voltage regulation, the voltage at secondary side is done by a voltage divider using two resistors and the voltage is converted to digital encoded signal through 555 timer. The encoded secondary side voltage is transmitted to the STM32 microcontroller positioned at the primary side using a digital isolator, ADuM2401 (Analog Device, USA) quad-channel digital isolator. This is decoded by STM32 which checks the generated voltage on secondary and controls the UC3845 with turn-on and -off for voltage regulation.

For the isolation transformer, EE1312 magnetic core (TDK, Japan) of ferrite material is used and the turn ratio of primary and secondary was 22 and 27, respectively. A 10 pins of vertical type EE1312 bobbin (Dae Heung Bobbin Co., Ltd, South Korea) was used. The winding is done using $0.25 \mathrm{~mm}$ diameter tri-insulation wire (TIW) for the primary side, and $0.3 \mathrm{~mm}$ diameter general purpose copper wire for the secondary side. A details of winding was shown in Figure 3. To comply with the standards presented by the international medical device regulations, tri-insulation wire was used. The inductance of primary side was $0.51 \mathrm{mH}$ and leakage inductance was $0.28 \mu \mathrm{H}$. The inductance of secondary side was $0.93 \mathrm{mH}$ and leakage inductance was $4.97 \mu \mathrm{H}$. The inductances was measured at $100 \mathrm{kHz}$ using impedance analyser HP4192A (Hewlett Packard, USA).
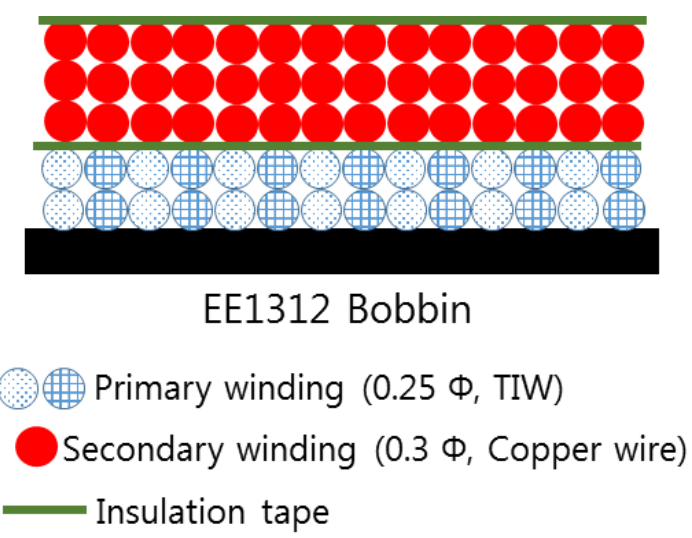

Figure 3. Winding details of transformer for push-pull converter.

The voltage of 12 volts generated at the secondary side was converted into 5 volts using LM7805 (Texas Instrument, USA) linear regulator. The voltage of 12 volts is used for the electrocardiogram amplifier, and 5 volts for electrocardiogram amplifier, 555 timer, digital isolator, and supervisor circuit to detect an invalid operation (Figure 2). 


\subsection{Bio-signal measurement unit}

To measure the cardiac signal, 1-Channel electrocardiogram (ECG) amplifier is configured. Figure 4 shows the schematic of the electrocardiogram amplifier. For the preamp which directly contacts with patients, instrumentation operational amplifier INA128 (Texas Instruments, USA) was used. This amplifier has a 1010 Sof input impedance, $50 \mu \mathrm{V}$ offset voltage, $0.5 \mu \mathrm{V} /{ }^{\circ} \mathrm{C}$ drift, $120 \mathrm{~dB}$ of common-mode rejection ratio, and excellent noise characteristics.

For the right-leg driver and an additional amplification, LMV324 (Fairchild Semiconductor, USA) precision dual Rail-to-Rail output operational amplifier were respectively used. A two first order passive low- and high-pass filter consisted of resistor and capacitor was connected in series for filtering of the cardiac signal. The bandwidth of the bandpass filter which consisted from two passive filter was in range of $0.75 \sim 300 \mathrm{~Hz}$.

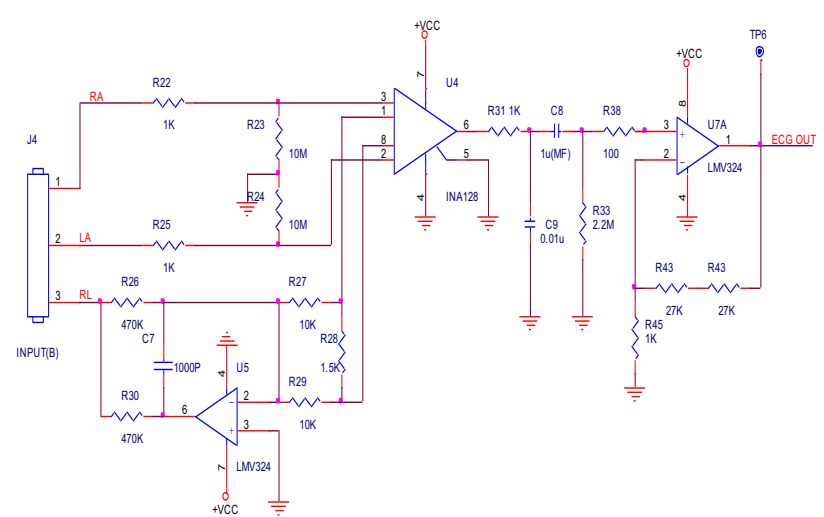

Figure 4. Schematic of 1-channel electrocardiogram amplifier.

The measured electrocardiogram signal is encoded into a digital signal using AD7741 (Analog Device, USA) voltage-to-frequency converter, and transmitted to the main control unit through ADuM2401 (Figure 2). The transmitted signal is input to STM32 which is then encoded and stored to the micro-SD card using DMA channel. The stored ECG data can be viewed in a personal computer (PC) using a custom made viewer.

\subsection{Testing the implementation of isolation barrier}

The implemented circuit was tested with patient simulator (Model\# 217A, Dynatech Nevada Inc, USA) and on two power conditions such as 'Charging Start' and 'ReCharging' status. The 'Charging Start' state is where the capacitor charged voltage is in 0 volt with no energy charged and the 'Re-Charging' state is a segment where the energy loss occurred by the natural discharge of inside of the circuit's time constant after full recharge is restored. The logged ECG data in the memory card was extracted using a custom maded ECG viewer to text file. Two datas that before and after application of isolation barrier were compared with MATLAB (Mathworks, USA) software.

\section{Results}

The implemented circuit is shown in Figure 5. The overall size which includes the 3 units is about $9 \times 11 \mathrm{~cm}^{2}$. The area of the proposed circuit was larger about $20 \%$ than prior circuit. The output of the push-pull converter is confirmed to generate stable output voltage of 12 volts within the input voltage range of $9.5 \sim 12$ volts. Load and line regulation of the push pull converter was $0.40 \%$ and $0.87 \%$, respectively.

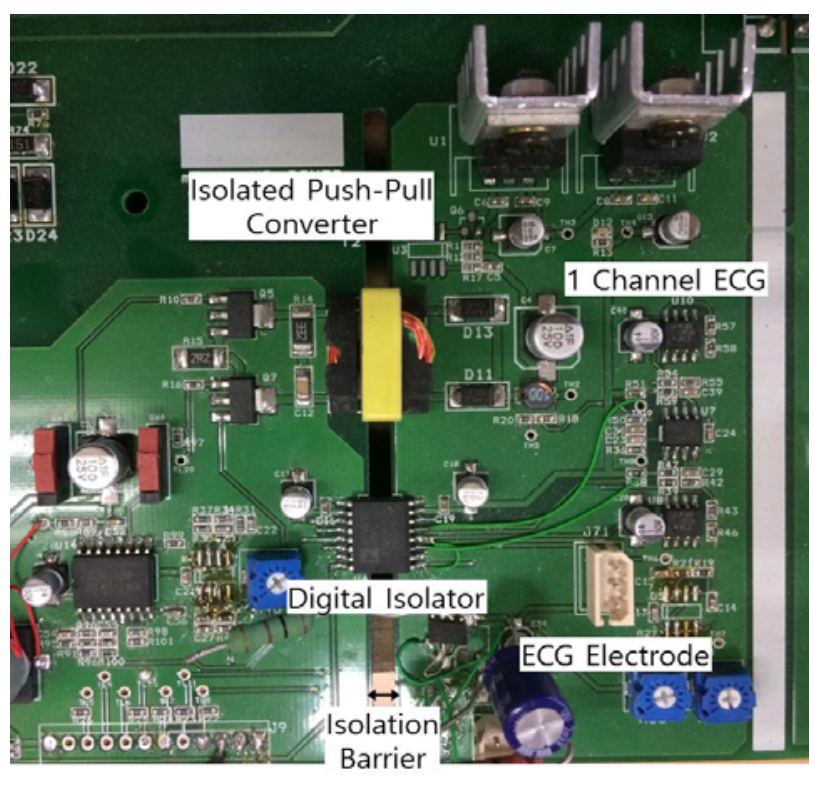

Figure 5. Picture of the prototype implemented units.

Figure 6 shows the custom made ECG viewer. This program could plot entire and enlarged waveform of the electrocardiogram, and record the status of the system and detection results according to the elapsed time; such as Power on/off, ECG lead, Analyzing, Shock advised, Press shock, Ventricular fibrillation (V-Fib), Asystole, Charging, Discharging, and etc.,

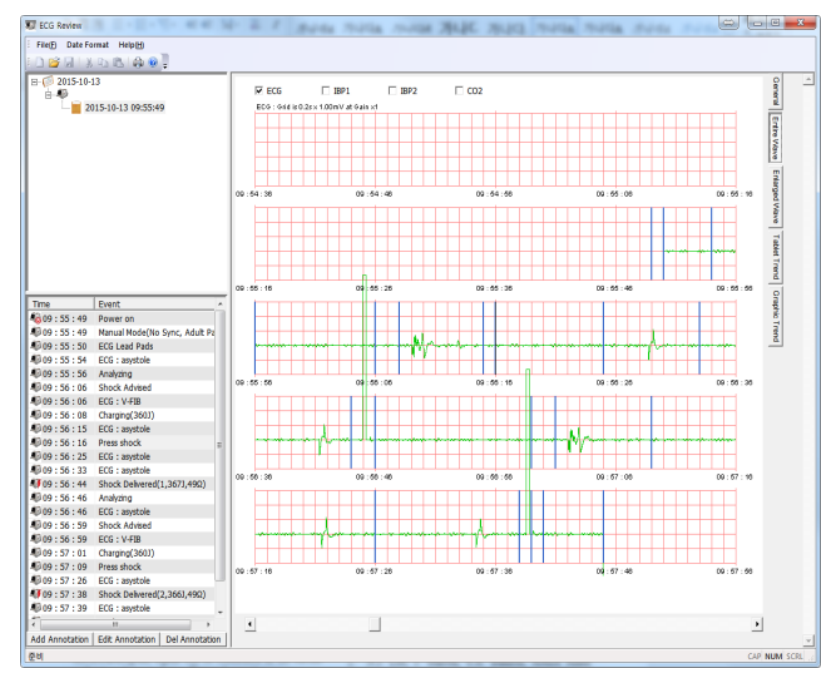

Figure 6. View of a custom made electrocardiogram software. 


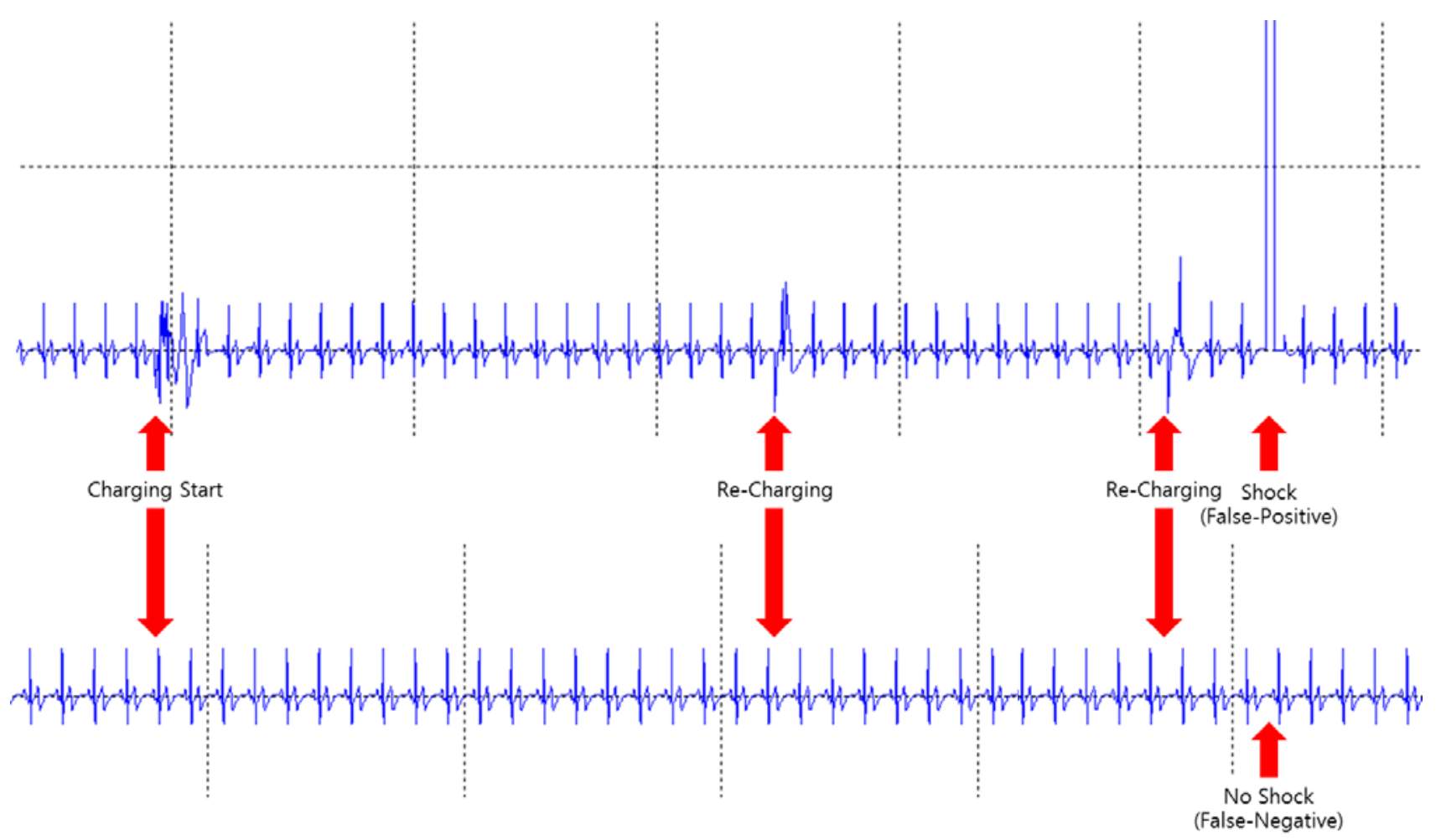

Figure 7. Comparison of the electrocardiogram signal between before (upper) and after (lower) application the isolation barrier.

Figure 7 shows the results of before and after application of the isolation barrier. Before applying the isolation barrier, distortion in EEG signal was occurred at both of the 'Charging Start' and in each of 'Re-Charging' status (Figure 7 upper). Also even in normal situation, an output signal for defibrillation is generated by the distortion (False-Positive condition) from the decision of integrated algorithm inside the STM32 microcontroller to detect and decision a shockable rhythms or not. This situation could be fetal to the normal heart because these energy delivery casuses fibrillation even to a normal person. Especially, the signal distortion is more severe in the 'Charging Start' state compared to the 'Re-Charging' state due to the voltage drop of the battery and high current flows into the uncharged capacitor for faster charge.

After applying the isolation, distortion in ECG waveform was almost disapeared and eliminated (Figure 7 lower). Also the false-positive condition did not occurred.

\section{Conclusions}

In this study, we proposes a method to attenuate biosignal distortion generated in high power portable medical devices. By applying galvanic isolation between the main control unit, power unit, and bio-signal measurement unit, the signal distortion on bio-signal generated during energy charge is eliminated.
Although the size of the circuit is about $20 \%$ bigger than the size prior to applying the galvanic isolation, this is considered to be overcome by designing a sophisticated printed circuit board (PCB) and downsizing the area of other circuits. Also this approach can reduce the additional time and cost for developing a shockable rhythm detection algorithm to deal with signal distortions. Therefore it is considered that this can be widely applied to small and medium sized medical device companies.

\section{Acknowledgement}

This research was supported by the Ministry of Trade, Industry \& Energy (MOTIE), Korea Institute for Advancement of Technology (KIAT) through the Encouragement Program for The Industries of Economic Cooperation Region (Grant number R0004491).

\section{References}

1. M.Y. Smith, J.D. Depue, C. Rini C, Pain Med. 8, Suppl 3 (2007)

2. N.J. Lee, J. Starren, S.A. Bakken, AMIA Annu. Symp. Proc, 1021 (2005)

3. G. Pistoia, Batteries for Protable Devices (Elsevier, Rome, 2005)

4. K.M. Conrad, P.A. Reichelt, S.A. Lavenderm J. Gacki-Smith, S. Hattle, Appl. Ergon. 39, 6 (2008)

5. A.L. Hansell, M. Blangiardo, L. Fortunator, S. Floud, K.D. Hoogh, D. Fecht, R.E. Ghosh, H.E. Laszlo, BMJ, 347, f5432 (2013)

\footnotetext{
$\overline{{ }^{a} \text { Corresponding author: hskim98@ }}$ kku.ac.kr
} 
6. K.G. Kanz, M.V. Kay, P. Biberthaler, W. Russ, S. Wessel, C.K. Lackner, W. Mutschler, Resusci. 62, 2 (2004)

7. L.A. DeLuca, A. Simpson, D. Beskind, K. Gral, L. Stoneking, U. Stolz, D.W. Spaite, A.R. Panchal, K.R. Denninghoff, Annls Emergen. Med. 59, 2 (2012)

8. P.F. Meyer, P.D. Gadsby, D. Van Sickle, W.E. Schoenlein, K.S. Foster, G.P. Graber, Med. Biologi. Eng. Comput. 43, 2 (2005)
9. D.M. González-Otero, J. Ruiz, S. Ruiz, U. Irusta, U. Ayala, E. Alonso, BioMed Res. Int., 2014, 865967 (2014)

10. M.I. Sobhy, A.E.D. Shehata, Int. Bifurcation. Chaos, 10, 12 (2000)

11. International Electrotechnical Commission, IEC60601 3rd Ed. (2013) 